\title{
Traditional New Zealand Mäori Instruments, Composition and Digital Technology: some recent collaborations and processes
}

\author{
IAN WHALLEY \\ The University of Waikato, Private Bag 3105, Hamilton, New Zealand \\ E-mail:musik@waikato.ac.nz
}

\begin{abstract}
This paper examines the integration of traditional New Zealand Mäori instruments with digital music technology, and the use of these instruments in making new works. The focus is on the work of performer/composers Hirini Melbourne and Richard Nunns, as well as recent collaborations that Richard Nunns has undertaken with some composers and musicians in genres other than Mäori music. Aesthetic, practical and cultural considerations in the composition process are explored.
\end{abstract}

\section{INTRODUCTION}

Composers and musicians create works that reflect and are part of their environment and culture. In seeking an artistic voice, identities are established, maintained and negotiated by individuals and groups. This may involve deciding what one is not, on the way to establishing who one might be. Douglas Lilburn (1915-2001), for example, regarded as the pioneer of New Zealand electroacoustic music, abandoned writing orchestral works after completing his third symphony in 1961 (Norris and Young 2001). Lilburn found that electroacoustic music lacked European cultural baggage because audio samples from the local environment could be fused with electronic sounds, making it possible to create a unique New Zealand soundscape (Burke 1996). In a similar search for a New Zealand voice, Phil Dadson with the group From Scratch (Nicholas 1993) paid homage to the "doit-yourself' New Zealand ethos by using 'home-made' instruments in a cross-cultural context. The group incorporated Polynesian rhythms played on purposely constructed and tuned percussion instruments made from PVC plastic pipes (Dart, Elmsly and Whalley 2001; Whalley 2004a).

Recently, the cultural/environmental exploration of a New Zealand voice has seen the revival of traditional New Zealand Mäori instruments. The pioneers were performer/composers Hirini Melbourne and Richard Nunns. Their first CD, Te Ku Te Whe, the result of a long period of research and re-invention, was released in 1994. Te Hekenga-ä-rangi (2003), their second and final CD/DVD completed just before Melbourne passed away, extended the instrumental tradition through the application of digital music production techniques.
In tandem and subsequent to this work, Richard Nunns has worked with a range of composers and musicians to explore the integration of traditional Mäori and Western instruments. Partners have included the New Zealand String Quartet, the New Zealand Symphony Orchestra, Jazz and Rock groups like Urban Taniwha and Moana and the Tribe, 'art music' acoustic composers such as Gillian Whitehead (1998), Helen Fisher (2000), Phillip Brownlie, Brigid Bisley, and Martin Lodge (2004); and electroacoustic composer/musicians like Ian Whalley (2002, Nunns and Whalley 2004), John Rimmer, and Elio Martusciello (Cooper, Nunns and Martusciello 2002).

Based mainly on this work, and an extended interview with Richard Nunns (Whalley 2004b), the paper examines the use of traditional instruments in a variety of compositional settings, including techniques of integration using digital technology. Beginning with a brief introduction to the instruments, it looks at how sound and performers are included in the compositional process; cultural/environmental influences; the integration of traditional and international idioms; and some of the hybrid outputs resulting from this process. All quotes herein are from Richard Nunns, except where otherwise indicated.

\section{INSTRUMENTS}

The two CDs, Te Ku Te Whe (1994) and Te Hekenga$\ddot{a}$-rangi (2003), are the best sonic records of the use of traditional Mäori instruments. In the $\mathrm{CD}$ notes of $T e$ $K u T e$ Whe is a description of the instruments played on each track. Te Hekenga-ä-rangi includes a DVD of Richard Nunns speaking about the cultural use of instruments and demonstrating how they are used.

Buchanan and Kaa (2002) note that the instruments fall into two broad categories: blown instruments such as flutes and trumpets; and struck instruments such as gongs. All of the instruments Nunns uses are made primarily from wood, seashells, stone or bone; or other materials found in the natural environment.

Most of Melbourne/Nunns' hand-made instruments are the outcome of a thirty-year period of research to collect and reconstruct a music-making tradition that had lapsed with the European settlement of New 


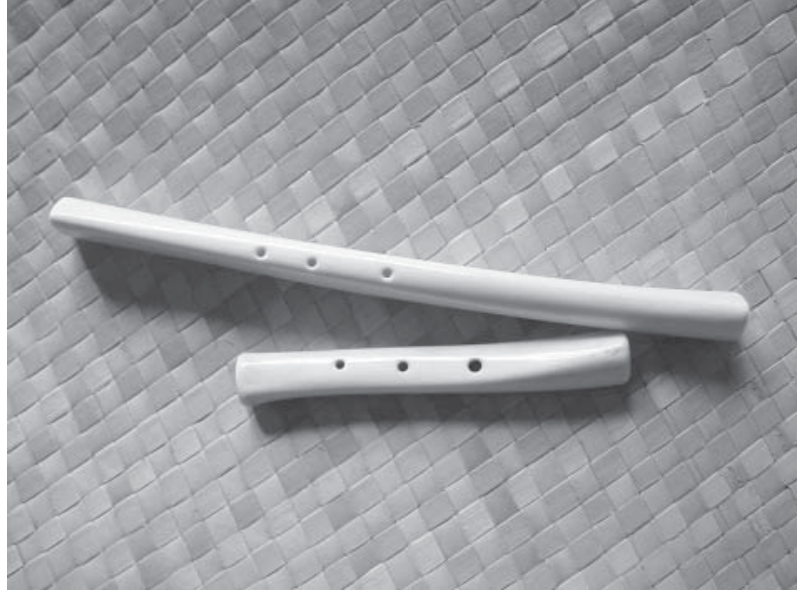

Figure 1. Koauau: flute.

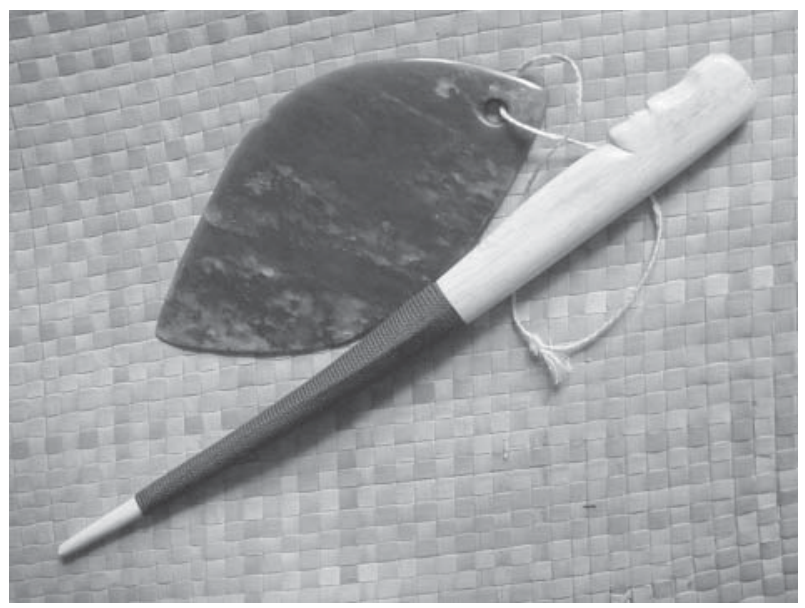

Figure 2. Pahu pounamu: gong.

Zealand (King 2003). Carver/instrument maker Brian Flintoff was the silent partner in this research process. Flintoff (2004) recently launched his long-awaited book, Taonga Püoro, Singing Treasures: The Musical Instruments of the Mäori, the definitive text on this recent work.

As few instruments used before European settlement were available to contemporary musicians, some instruments existing only in museums, most of Richard Nunns' collection of approximately eighty instruments are then reconstructions resulting from the collective research process. Similarly, access to pre-European instrumental practitioners was impossible, so methods of performance also had to be rediscovered. This involved dialogue with Mäori elders, experiments in instrument design, and trials of how instruments might sound when used.

Nunns notes (Whalley 2004b) that he could never claim that the way the instruments sound today is exactly as they were in pre-European times, but within what he calls a 'vector of probability' he is

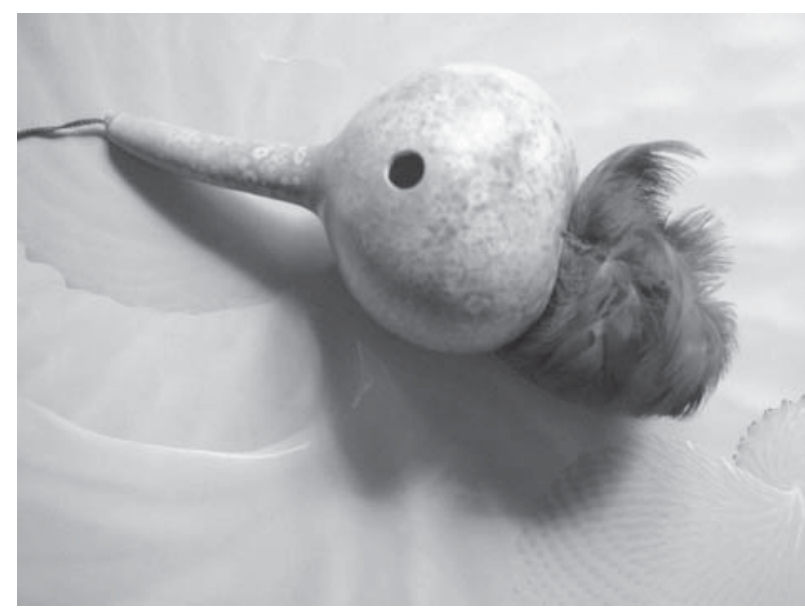

Figure 3. Poiawhiowhio: whistling poi.

certain they are close to what the sound and performance gestures might have been. Some sonic examples of the instruments can be found at http://www.inza. co.nz/RN_home.html

Acoustically, most of the instruments have a very small dynamic range, and many hardly register in the recording process without significant volume/gain being added. However, the dynamic range between different instruments is significant, making it difficult to combine many different instruments into large ensembles in live performance.

The few melodic instruments used, such as the flutelike koauau, have a limited pitch range. For example, holes drilled in the short sound tube allow for only four notes. Melodic gestures are therefore small and subtle, and the performance quality is often of as much interest as the melodic content. In combination with instruments being made from natural materials, the resulting sound of the instruments is generally characterised by warmth and delicacy.

Tuning is individual to each instrument rather than an absolute pitch reference, as is relative tuning between notes on an instrument. Further, there is no written notation system for performance, and no systematised method of combining different instruments into extended ensembles. Improvisation then remains a main method for making music.

\section{CULTURAL AND ENVIRONMENTAL INFLUENCES ON PLAYING}

Traditional instrumental performance is influenced by a cultural response to the environment. Nunns suggests that the way the land speaks to performers can be heard in regional Mäori tribal dialects: the 'music of their speaking':

Tuhoe live in the bush that is not deciduous. Mist constantly wets the bush. Everything is padded and quiet. Water drips. The area has one of the heaviest coatings 


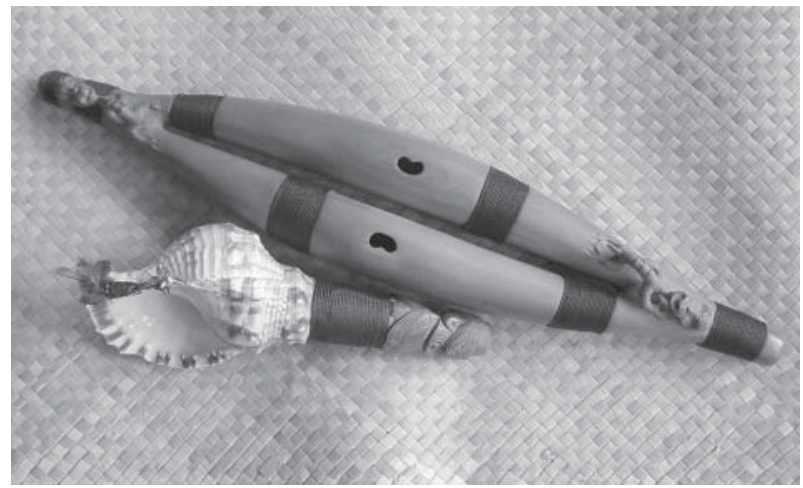

Figure 4. Pütorino (flute) and pütätara (trumpet).

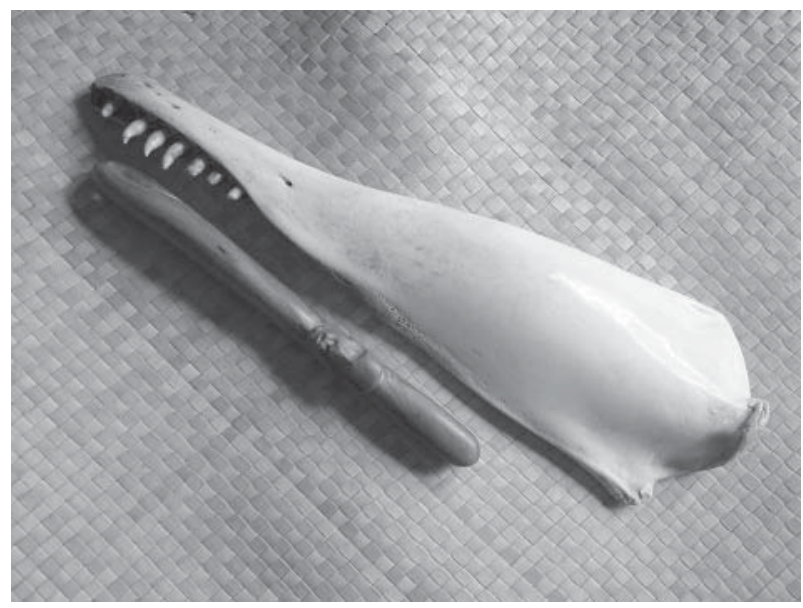

Figure 5. Tumutumu: percussion instrument.

of rainforest left in the world. They (the people) speak slowly, and they speak quietly, and have a lilt that echoes the movement of slow moving water.

You go to the far North and there is a strip of land that runs from say Kaitaia to Cape Reinga that is forty-five odd miles long, and at its greatest point about three or four miles wide, some of it is a lot narrower. Wind blows one way or it blows the other. I don't think there is ever a time when the wind doesn't blow. Those people up there speak like the wind.

That is what we have used in the absence of regional playing styles. When young people from various areas say 'how do I play', one of the things we tell them is, 'go back and listen to the environment, go back and listen to how your people speak... you live amongst this and it belongs to you. This is your orchestra. This is your music. See what you can do in the way to mimic those voices with the instruments'.

The way people sing has also been a direct teacher as to how the melodic instruments should be played:

The great teacher for the voice of the instruments is the lilt in the way people sing. We haven't got recorded examples and we haven't got living teachers. Singing has been our great teacher, has to be our great teacher. Because melodic instruments are known to have accompanied song, the sobbings, the cryings, the suppressed emotions, the shivering of the voice and so on that you hear in singing are what you build into the instrument's performance.

Apart from vocal and language references, a direct response to the environment influences instrumental performance:

. . . bird song, wind, and 'the breath of the land' are concrete and abstract ways you might come across stylistic approaches to the melodic instruments ... I don't think you can play the instruments without a personal connection to the land, and that requires acute listening.

Apart from this research, performers bring musical experiences and skills to the tradition of Mäori musical instruments from other genres. Nunns, for example, played trumpet and flute in Jazz ensembles, and was involved with rock music, rhythm and blues, and orchestral work before working with traditional Mäori Music instruments. These experiences he also draws on when working with composers from different genres.

\section{LIVE PERFORMANCE, IMPROVISATION, CROSSOVER WORK}

Nunns has worked with a number of acoustic 'art music' composers such as Gillian Whitehead (1998), Helen Fisher (2000) and Martin Lodge (2004) to create new 'crossover' works. Although outside the digital domain, this work is touched on here to provide an insight into methods of working with composers both within and beyond the Mäori music tradition.

International composer Gillian Whitehead's work with traditional Mäori instruments is part of an exploration of her own Mäori heritage. Hine Raukatauri, realised in 2003, features Richard Nunns on Mäori instruments and Alexa Still on Western flute. The work combines the flute traditions of two different cultures. The process of making this piece is typical of the way Nunns works with composers, the first step being to provide them with a sound archive, and allowing them to familiarise themselves with the characteristics of the instruments: their pitches, timbre and gestures.

In making a work, the composer must leave sonic spaces for the performer to improvise at the level of musicianship that they are capable of. More specifically for Nunns, this has meant providing himself licence not to read a note of Western manuscript, and never to count metrically:

I tell all composers that I work with, that you need to know this about me: it is no good writing for me because I can read but I refuse to, and I don't count any more. I am an improvising musician. I draw on my skills of 
years in the Jazz field that allow me, or give me possibly a misguided confidence in my abilities, to improvise in a multitude of situations.

As a result, if the work is to be realised independently of a recording, the Mäori instrumental improviser/ exponent for which the work was written has to be present, and exact repetition between one performance and another is impossible. Each performance will simply be different, and the element of difference is accepted and celebrated.

Composers must then leave blocks within a work, or provide a macro structure, into which the performer can improvise. The improvised results can come about in a number of ways, accepting the limitations of the traditional instruments used:

... they can leave an open hole for me and discuss with me how they wish to work, or they can leave it totally open to me. More often someone like Gillian will talk to me at length about what she wants: she will name an instrument and give a length of playing time. Because of the non-counting issue, I generally advise composers to not have me making pinpoint entrances or exits. Some of these instruments technically are difficult to start up on cue. It means having to work with the frailties or strengths of these instruments.

Similarly, tuning issues must be accommodated, since the instruments do not adhere to standard Western equal temperament scales or pitches. Nunns credits his ability to fit with live performer and instruments in various styles to his years of improvisation.

... about eighty per cent of the voice of the instruments are actually generated within you in ways that I can't even begin to describe when I'm teaching people ... you are searching for a sound within you. I often say one of the biggest impediments to the enjoyment of music in a global sense is to have perfect pitch, because it applies a Western tempered scale that destroys your ability to hear the music of the world with any enjoyment or facility: (alternative instruments then) somehow seem to be from another planet.

Beyond 'art music' composition, Nunns has also worked with rock and jazz groups, requiring different techniques to make improvised compositions. He has been a reasonably constant member of Moana and the Tribe, who use a large sound amplification system. The traditional instruments are also amplified in live performance:

I have had to fight for my space in there and over the years, but the band has learnt to create dynamics and holes whereby the instruments fit because they are voices that Moana wants, being part of her music and culture. When the band is really excited and are over-amped, there are a couple of percussion instruments I used that cut through everything. But in terms of flutes, we have to find spaces. Because she (Moana) has largely now settled on a band that is acoustic, albeit through a PA, the particular musicians know what I do, they know where I fit. There is a great deal of sympathy.

The 'free' Jazz group Urban Taniwha, a collaboration that has included musicians Marilyn Crispell and Waimihi Hotere, is a further means of collaboration for Nunns. The genre is most suited to his background as a musician, with all work being primarily improvised. Nunns notes:

I am there to do what I do and they are ultra conscious of the space that I occupy and the volume, or the lack of volume that I am capable of, so it's a very sympathetic working environment; the highest level of improvisation that is person-to-person not instrument-to-instrument. It is a musical relationship and the band is worked up in semi rehearsal in thematic blocks, but every performance is improvised. The band is a musical-personal relationship that has grown. More important than anything, is learning to listen.

On the ethos of improvisation that makes this possible, Nunns recalls:

I remember Marilyn Crispell ran the most extraordinary workshop for students at the Wellington School of Jazz, and she never mentioned music once in two hours. She spoke about love, she spoke about attending, she spoke about listening, all of those things except the word music. It was about improvisation, it was about the sharing, it was about the relationships that you create that are expressed through instruments that you play.

Finally, of recent improvised/collaborative work that crosses from the jazz into the classical field, Nunns says:

Most of my recording coming up is with pianists. You would think it would be the most unlikely instrument, but I'm working with people like Marilyn Crispell, Mike Nock, Paul Grabowsky, and Judy Bailey (Bailey, Garden and Nunns 2004). They have the ability to create clusters of sound that fits with what I can provide. They also have ways of playing within the piano, which I know is not new, but they have a way of playing and dampening things that is sympathetic, that matches volume beautifully.

\section{DIGITAL PRODUCTION AND CONSTRUCTION}

Hirini Melbourne and Nunns' first album using primarily traditional instruments, Te Ku Te Whe, or the 'Woven Mat of Sound', was released in 1994. Recorded digitally, the intention was to take the listener into a pre-European world, structured by the moods of nature, by mythology and history; to evoke in sound the relationship between Mäori music and the sea, the land, and the wind.

Although the duo was offered a month in the studio, the material for the CD was recorded in a short working day, mostly in the morning. The players improvised the material live, with reverb, EQ and 
compression being added in the production process. Only one section was multi-tracked, adding a loop of a deep bass gourd, because Nunns could not physically keep up the long sequence required for the track. Material for the $\mathrm{CD}$ was therefore limited by what the duo could realise in real time.

Nunns comments on the improvisational approach to creating works:

One would have to say in the way we worked, and the way I work now, it is utterly pointless for us to do second or third or fourth or fifth takes to try to improve on something. You don't get something better, just something different. If we don't nail it in one, all you are going to get is a confusing plethora of choices by putting down more stuff.

Musically, the sound of the CD is based in traditional Mäori musical forms, without directly quoting material:

Our work seemed to be organic, as it was rooted in tradition. We deliberately alluded to traditional forms and melodic sequences to save ourselves the difficulty of having to approach tribal groups to ask for permission, or cause offence. I think it struck many heartstrings because it sounded so old. It was to celebrate the voices from the past: to let people hear these extraordinarily beautiful instruments in the sense that it is a voice that could come from nowhere but this country.

The album balances a melodic and a rhythmic/ textural approach to composition. Facilitated through digital technology, it allowed instruments with a low dynamic range to be combined and boosted without adding excessive noise, bringing their intense intimacy forward in the mix.

The second album the duo made with Aroha YatesSmith, Te Hekenga-ä-rangi (2003), departs significantly from Te Ku Te Whe (1994) in the production and compositional approach used. Partly this reflects the circumstances in which it was made, and partly that Melbourne and Nunns' work had developed to include a wider range of instruments. The album includes larger ensembles, extensive multi-track layering, and effects manipulation: particularly of reverberation space and panning. Nunns recalls on making the album:

One has to understand that Hirini was near death. He was twenty-one days away from passing, and he could hardly sing, which was his main role. Sadly, I play virtually all the instruments you hear because he didn't have the respiratory strength to play.

This was part of the reason that multi-tracking was extensively used. As important was the idea behind the album, and the direction Melbourne wished to take with it. The CD title is about an ancient people who originated in the heavens and then occupied Aotearoa / New Zealand. Te Hekenga-ä-rangi reflects the sense of their voices, the voices of the gods, passed on from the realm of the spirit. This spirit is in the stones and shells that are melded through playing into evocative sonic structures on the album, in addition to female deities whose stories are woven into the texture through song. Aroha Yates-Smith provides the female voice, who also contributes thematically to the album through a knowledge of Mäori feminine spirituality.

Apart from written text and small melodic fragments of traditional songs, material for the album was improvised and then built up in the production process through collective discussion:

An interesting process over the week was the collaborative approach. Aroha Yates who sings on the CD provided text that they (Hirini and Aroha) both worked over. Hirini of course provided other song texts and some of the melodic lines that are purely traditional. My input was rhythmic in some cases, setting up rhythmic patterns and also playing virtually all of the instruments. In discussion we decided any deliberations and anything related to the album was to be done three ways.

On the process of building up the layers, Nunns says:

... as performers you are working in the dark, in the sense that you have no capacity for hearing the layers in a recording situation. Mostly it became Steve Garden's job, the studio engineer/producer, to build up the layers, largely on the instructions of Hirini, a little from me and a little from Aroha ... Hirini had a vision and because he was so close to death we bowed to his wishes in that sense.

To get new ensembles of instruments to fit together beyond what the players may improvise individually, volumes and EQs were extensively manipulated, with instruments that are nearly silent acoustically appearing strongly in the final mix. Further, the manipulation of the spatial effects is an integral part of the structure of many of the compositions on the $\mathrm{CD}$, creating a new hybrid style that is as much a reflection of contemporary technology as traditional practice.

\section{FURTHER DIGITAL CONSTRUCTION: MEDIUMS AND METHODS}

The move towards combining improvisation with editing after the fact to create new works is also reflected in Te Hau Kuri (Dog's Breath), one of the last pieces Melbourne and Nunns completed, for the CD New Zealand Sonic Art III (2002). The short audio sequences used here were recorded onto a stereo track, with both players improvising using similar instruments for each of the nine different takes. The samples were subsequently used to create a large ensemble through digital production techniques. Apart from pan, EQ, compression and volume alterations being added to get the ensemble to mesh, the recorded segments were left intact. 
Melbourne then created the compositional structure of the work using Protools. Guiding the generation and placement of the samples, Melbourne writes in the notes for the CD New Zealand Sonic Art III:

Every valley, every place, has a special wind. This piece results from a long association and fascination with the chilling south wind that blows down the Ruatoki valley. It is known locally as the wind of Okiwa, which emanates from the breath of Mariko, a dog that belonged to the high priest Taneatua of the waka (canoe) 'Mataatua' that landed at Whakatane around 1350 AD. After Mariko died his spirit became the guardian of a pond that bears its name, in the upper reaches of Te Urewera. When stirred, the dog would rise to the surface to bark. The wind from Mariko's breath causes the Okiwa wind to rush down the valley, accompanied by mist. The wind saves the crops in the valley from being destroyed by frost.

The sounds of the nine traditional Mäori wind and percussion instruments used in this piece were deliberately chosen and arranged to retell story of the Okiwa wind musically. The instruments, in order of appearance in the piece are: Kü (mouth bows played by two people), Pütätara (wind effect used here non-traditionally), Pütätara (conch shell sounded traditionally), Pükaea (natural wooden trumpet), Pütorino ( a small version heard here as a flute sound, but may also sound like a trumpet), Pümotomoto (a longish flute), Porotiti (a spinning disk - blown or breathed on), Pangura Whakatangi Tangura (resonant rods held across the mouth and tapped with another rod), Roria (a mouth harp that can be made of bone or wood) Kakara (a rattle tied around the neck of the hunting dog at night), Pütorino (a double flute, a larger version played here), Pütorino sequence (with vocal added), and $\mathrm{Ku}$ (mouth bows again played by two people).

Extending this approach and using similar production techniques, but manipulating the source material extensively to create new instruments and sonic textures, Ian Whalley (2002) used a range of samples recorded by Richard Nunns to make the work Kasumi (2002). The work explores Asia/Pacific similarities in musical sound through the integration of Japanese aesthetics. The notes state:

The short instrumental samples used here are from seven New Zealand Mäori instruments played by Richard Nunns ... The Japanese text for this piece is from The Manyoshu, number 4,290 by Otomo no Yakamochi (718-785) written on 23 February 753. The season is early spring, and the poem contrasts internal sadness with new beginnings. In thirty-one syllable Tanka form $(5,7,5,7,7)$, the idiom was commonly used to concisely capture and complete a moment or occasion, each phrase summarising one image or idea.

A main difference in compositional technique from the Melbourne/Nunns work was that the recorded instrumental fragments were loaded into a sampler. Extensive pitch and real-time sound transformation techniques were then applied, and the altered sounds subsequently blended and contrasted with the original material to create the structure and dynamic of the work. The sampler also allowed the instruments to be performed in ways that were not physically possible, such as two octave transpositions and extended pitch bending.

Richard Nunns has also recently begun to explore the integration of traditional instruments with electronics in live performance, relating:

My first experience of working with an electronic musician was in Rome with guitarist Mike Cooper. He brought along electroacoustic musician Elio Martusciello. I was apprehensive that I was just going to be obliterated from the stage, with my pre-conceptions of what electroacoustic music would do to me and my delicate, subtle musical instruments that only have a four note melodic range, and very little dynamics. However, the evening was a revelation to me, and the results have come out as an album (Copper, Nunns and Martusciello 2002). Elio intuitively knew what I was about and became the immediate foil, or accompaniment to what I was doing. His gadgets I know nothing about, but to me the sounds were the gentlest, softest most extraordinary flutterings; they were like wings, they were like insect noises and sounds, but mainly of movement rather than insect singing. I was won over completely.

Recently on a visit to the United States in 2004, I worked with Richard Teitelbaum. As with Martusciello, he also had a subtle and sensitive touch with his electronic equipment, and great sympathy with the instruments I used. We have plans for a future project in 2005, when I will also work with New Zealand electroacoustic musician Annea Lockwood who is now based in the USA.

In New Zealand, other electroacoustic composers have also begun to explore the integration of traditional instruments and soundscapes through the 'instrument and tape' medium. John Rimmer, for example, recorded a number of instrumental samples from Richard Nunns, subsequently manipulating them to create the tape section of Cosmic Wind (2004). In the performance of the work, Nunns improvises over Rimmer's material using a variety of traditional instruments.

A similar approach was taken in Pukera (Nunns and Whalley 2004), although the 'tape' section was arrived at partly by using a generative compositional system developed by Whalley. Here, Nunns again first recorded short audio samples that were then processed and developed electronically. Whalley next manipulated the fragments through digital audio processing, and juxtaposed processed and natural sounds to create the structure of the piece. Unlike Rimmer's work, Pukera requires Nunns to use only one instrument to improvise the live performance: a small pütorino. Nunns plays this wind instrument using a range of techniques to enhance the texture and melodic shape of the work. 
Finally, a recent Nunns/Whalley collaboration was named PiWeCS: a Public Space Interactive Web-based Composition System. This project began from a desire to preserve examples of different instruments being played, but moved well beyond this. Since access to leading players of the traditional instruments was limited, and many of the instruments unique, the initial intentions of the PiWECS project included (Whalley 2004c):

... finding ways to overcome barriers of time and scarcity to allow lay people to discover and explore some of the instrumental sounds in a public space, independent of passive reception through live performance and the $\mathrm{CD}$ medium; to allow them to explore the combination of some of these instruments in a compositional and interactive context; and to allow the possibility of extending the instruments in an electroacoustic context as a way of exploring a new hybrid sonic landscape unique to New Zealand.

To implement this, Nunns provided a range of performances on different instruments, recorded into individual samples. The technical/compositional infrastructure involved developing a web-based interactive system. The aesthetic concern was to increase a sense of dialogue between human and machine agency that was lacking in many interactive systems. It was achieved by adapting Paine's (2002) notion of a conversational model of interaction.

The machine implementation of PIWeCS was implemented through integrating intelligent agent programming with MAX/MSP on the server side. Human input is through a web interface using FlashMX to build an augmented mixing board. The system allows a conversation to be initiated and continued by participants through arranging the audio samples, and building larger compositional structures, over time. It also allows the extension of a composition through the electroacoustic manipulation of the source material. An integrated Java-based multi-agent system, scripted with compositional knowledge as an 'expert system', acts as a guide and mentor for participants. In addition, the system accumulates user preferences and patterns, allowing the nature of interaction to be unique to each session, and the relationship between users and machine to deepen over time (Whalley 2004c).

Finally, recent work by Graham Hill at the University of Waikato, funded through a New Zealand Royal Society grant, has begun to look at the application of physical modelling and wind synthesis techniques to replicate a range of koauau (flutes). The intention is to develop models that will be able to play beyond the pitch ranges and other capabilities of the original instruments.

\section{FILM AND DOCUMENTARY}

The exploration of the New Zealand soundscape through traditional instruments, and their use in other contexts, extends to numerous documentaries and film scores. Some of these reflect the Mäori thematic content of the film.

Joe Malcom, for example, was one of the first practitioners to provide traditional instrumental material, in combination with the New Zealand Symphony Orchestra, for the film Utu (1983). Hirini Melbourne provided samples for Once Were Warriors (1994), and the film Whale Rider (2002) includes a voice/ percussion loop from the album Te Ku Te Whe. Nunns observes:

When the whales call to the young girl and continue to call when she rides them, it seems to be a smudging of electronica, human voice and a $T e \mathrm{Ku} T e$ Whe sample. The work that we've done has been used in a multitude of different ways, from just music through to atmospheric ambient effect.

Apart from films with a Mäori thematic content, Nunns has provided material that can end up in the most unlikely places, through being manipulated or used as part of a sound texture. On his recent work for The Lord of the Rings Trilogy $(2001,2002,2003)$ that was shot in New Zealand, Nunns states:

In The Lord of the Rings, you won't even find my name on the credits there because it came through the sound design workshop. I did a morning's worth of stuff there. From what I have heard, I can recognise myself fairly unmorphed in a variety of places.

Nunns has also provided samples for composers to weave into scores for films in other cultural contexts, not all of which sit comfortably with him. The Land Has Eyes (2004), for example, is set in Rotuma, Fiji. Nunns worked with composer Clive Cockburn on the project, recalling:

I actually did stuff from about 11 o'clock until about 5 o'clock in the afternoon, virtually for the whole film. My first question to him was: 'what do the Rotuma's think about me providing music for their film?', because they would have music of their own.

Nunns has also become adept at improvising to moving images as a method of constructing documentary and short film scores, and feels comfortable with the approach. For The Flight of the Albatross (1995) Nunns worked with musical director Jan Preston, noting:

I really enjoyed working on that because it was the first time I ever played with the New Zealand Symphony Orchestra, with cans on my ears: me with a small flute soaring over the massive symphony orchestra was extraordinary.

\section{EXTENDING TRADITIONAL INSTRUMENTS}

Despite his many attempts to integrate traditional instruments into other musical genres and develop hybrid styles, Nunns largely holds to the original ethos 
of the research into the instruments, to protect their integrity:

... by and large I do not try and play outside the traditional form of the instrument, and I do not try to extend the instrument, try and deconstruct it, or extend its range. I tend to play within the voice of the instrument, and only in very rare circumstances have I tried to push them beyond what I think their limits are.

In practice however, it is sometimes necessary to attempt to explore this:

... I play about forty different instruments, and about eighty examples of those. I can set up a battery of instruments on a stage to play, and do a whole concert with ten seconds on each instrument. It would be a ridiculous run through however, so I've started to challenge myself by staying on one type of instrument, and on occasions trying to do a whole set on one instrument only to see what I can draw from it. This doesn't mean offensive or extraordinary acts of musical cruelty, just to try and play or breathe through it in different ways, to find extra resources within the instrument with care and thought and integrity.

Nunns does not have Mäori ancestry, so questions about his involvement with traditional instruments often arise. In response, he notes:

... it has been a passion and an obsession for the last thirty years: to want to know about these lost voices, these sounds. You wouldn't choose this path wittingly because it's awkward, difficult, politically incorrect, edgy and gritty. There's always an element of jealousy if you like, of uninformed ideological anger; but there's also enormous respect, support, cushioning, help, guidance and mentoring. Not in musical ways, but in Mäori ways: ways of being in a Mäori world which have been hugely attractive to me and still remain a wonderful learning curve. (Confidence is) built on that, and an established integrity about one's approach, knowing that (the instruments) are spiritual, highly valued, Тари (sacred), and restricted domain.

My journeys into other usages of the instruments has largely been alone, but bolstered by the fact that I am, by and large, highly thought of within the Mäori community, that I am held up and tolerated if you like, respected perhaps. I suppose there will be an intellectual debate at some stage about the appropriation and appropriateness of taking these voices into conversation with other genres, but it hasn't happened yet.

On the subject of appropriateness, Nunns adds:

I have a collection of about two hundred 'ethnic' instruments, some of which I can play competently, but I don't play them now, because I feel it is extremely disrespectful to the traditions that they came from. Even though technically I can do things with the flutes and trumpets, I know so little about the way in which they are placed within the cultures that I think it's trampling on other cultures to play them. This extrapolates to many things I hear in world music where you get virtuosic people playing instruments. I want to know how long this person submerged themselves in this culture and are they respected by the people, or is it just somebody with enormous musical/virtuosic skills imposing on them. It is a fine edge that I walk all the time.

In musical terms, on the use of traditional instruments in non-traditional contexts, Nunns muses:

In entering into a dialogue between disparate genres I couldn't be more disparate. I can only play four notes of melody. My whole conception of sound is about living within the bend and curve, living within tones in a very circumscribed playing field. But that's where the excitement resides and that's where the beauty and achingly wonderful sounds reside. There are people in the world who want to engage in that area. It's the personality that chooses to play with you or you choose to play with that makes it successful, not the instrument.

The recent approach of using the instruments in new contexts to create new styles is then largely left to collaborations. Drawing on the skills and talents of musicians, composers and producers from other music genres, these hybrids are the outcome of sympathetic dialogues that emerge between practitioners.

\section{CONCLUSION: NEW ZEALAND SOUNDSCAPE}

In the introductory notes for New Zealand Sonic Art III, Martin Lodge (2002) writes:

Forty years ago, New Zealander Douglas Lilburn established an approach to electroacoustic composition rooted in the investigation of environmental sound. The intention was to uncover the inner, spiritual values of natural sound and thereby develop an awareness of place ..

The revival of traditional Mäori instruments in New Zealand, particularly for Mäori people and for other New Zealanders who are sympathetic to this initiative, provides a voice that can only come from this country. When used in combination with digital technology and other genres or media, new hybrid styles are being evolved that reflect an attempt to reconcile a cultural past and a cross-cultural present.

Lilburn's notion of finding a New Zealand voice has not disappeared, but the world he sought to represent and the resources that can be drawn on to portray it have been expanded since the 1960s (Whalley 2004a). The resulting work allows the possibility of extending the New Zealand soundscape as an aspect of what it means to live in New Zealand at present.

\section{ACKNOWLEDGEMENTS}

Thanks go to Richard Nunns for providing the interview material for this article, and reading the draft. All photos, courtesy of Richard Nunns (http:// www.inza.co.nz/RN_home.html), used by permission. Photographer: Brian Flintoff, Nelson, New Zealand. 


\section{REFERENCES}

Buchanan, D., and Kaa, K. 2002. Traditional Mäori Music. Discover: Te Kohanga Taonga. http://discover.natlib. govt.nz

Burke, C. 1996. Douglas Lilburn: an interview. Music in New Zealand 29: 37.

Dart, W., Elmsly, J., and Whalley, I. 2001. A View of Computer Music: Auckland, Waikato and the Asia/ Pacific connection. Organised Sound 6(1): 11-20.

Flintoff, B. 2004. Taonga Püoro, Singing Treasures: The Musical Instruments of the Mäori. Nelson: Craig Cotton.

King, M. 2003. Penguin History of New Zealand. London: Penguin.

Lodge, M. 2004. Toru. Sound Lounge. Concert FM, Radio New Zealand, 7 September.

Nicholas, G. 1993. Pacific 321 Zero. NZFC Films.

Norris, M., and Young, J. 2001. Half Heard Sounds in the Summer Air: electroacoustic music in Wellington and the South Island of New Zealand. Organised Sound 6(1): $121-8$.

Nunns, R. 2001. Te Ara Puoro: the pathway of sound. Voices. The World Forum for Music Therapy 1(3). http:// www.voices.no/mainissues/Voices1(3)Nunns.html

Paine, G. 2002. Interactivity, where to from here? Organised Sound 7(3): 295-304.

Whalley, I. 2004a. Recent New Zealand Electroacoustic Music: nexus, flux, negotiation. Leonardo Electronic Almanac 12(8), August.

Whalley, I. 2004b. Interview with Richard Nunns, 9 June (unpublished).
Whalley, I. 2004c PIWeCS: enhancing human/machine agency in an interactive composition system. Organised Sound 9(2): 170-6.

\section{DISCOGRAPHY}

Bailey, J., Garden, S., and Nunns, R. 2004. Tühonohono: The Weaving, Rattle Records, RAT-D010.

Cooper, M., Nunns, R., and Martusciello, E. 2002. Play Live@ Cineclub Detour-Rome-Italy-18.6.2002. Hipshot Records, HIP-010, CD.

Fisher, H. 2000. Taku WanalThe Wheel Turns. Atoll Records, ACD203, CD.

Lodge, M. 2002. Liner notes, New Zealand Sonic Art III. Hamilton: University of Waikato, CD MDUW1202.

Melbourne, H., and Nunns, R. 1996. Te Ku Te Whe. Rattle, RAT D004, CD.

Melbourne, H., and Nunns, R. 2003. Te Hekenga-ä-rangi. Rattle, RAT DV010, CD.

Moana and the Tribe. 2003. Toru. Pirate Records / Sony Music, CD.

Nunns, R., and Whalley, I. 2004 Pukera. Unpublished. Premiered 28 July 2004, Campus Lunchtime Recital Series, University of Waikato. Organised Sound 10(3) CD.

Whalley, I. 2002. Kasumi. New Zealand Sonic Art III. University of Waikato, UWMD 1203: Track 5.

Whitehead, G. 1998. Ipu. Rattle Records RAT0007, CD.

Various. 2000. New Zealand Sonic Art 2000. Hamilton: University of Waikato, CD MDUW1200.

Various. 2001. New Zealand Sonic Art Vol. II. Hamilton: University of Waikato, CD MDUW1201.

Various. 2002 New Zealand Sonic Art III. Hamilton: University of Waikato. CD MDUW1202. 